\title{
TUMOR DE FRANTZ (TUMOR SÓLIDO-CÍSTICO DE PÂNCREAS)
}

Elias Jirjoss Ilias, Paulo Kassab, Osvaldo Antonio Prado Castro, Rodrigo Vincenzi e Nadim Safatle

Trabalho realizado na Faculdade de Medicina da Universidade de Santo Amaro

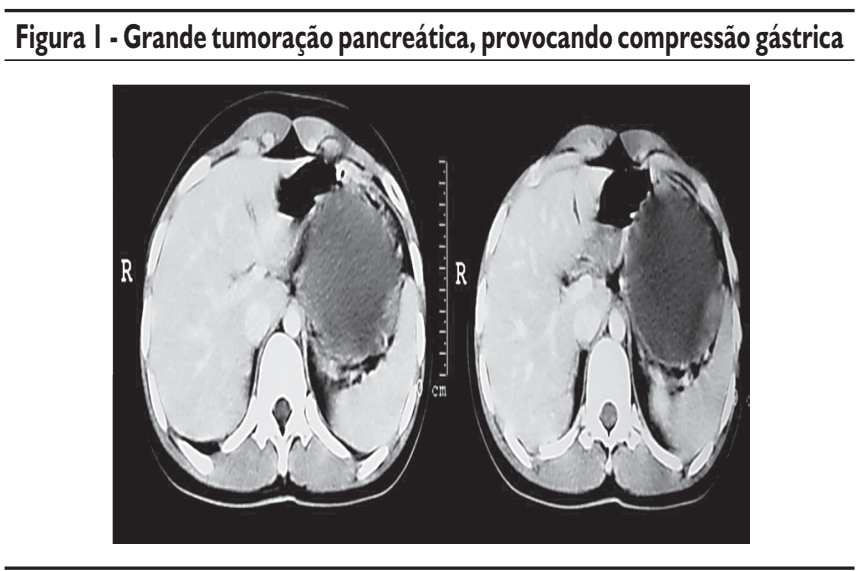

J.M.S.A, 23 anos, feminino, parda, natural de São Paulo. Admitida no Hospital Geral do Grajaú com história de dor em hipocôndrio esquerdo com irradiação para região epigástrica há quatro semanas, de caráter contínuo, com melhora parcial à utilização de analgésicos, acompanhada de náuseas pós-alimentares e surgimento de tumoração abdominal neste mesmo período. Não apresentava doenças prévias, história de trauma ou antecedentes cirúrgicos, além de não possuir na família casos de neoplasias.

Exame Físico: Encontrava-se em bom estado geral, corada, hidratada, anictérica, afebril, orientada e eutrófica. Propedêutica cardiovascular e pulmonar sem alterações, apresentando tumoração abdominal que ocupava a região do hipocôndrio esquerdo, estendendo-se para região epigástrica, com superfície irregular, bem delimitada, móvel e dolorosa a palpação.

Exames Complementares: Ultra-sonografia de abdome evidenciando tumoração com conteúdo cístico em retroperitônio, Tomografia Computadorizada de abdome apresentando tumoração proveniente de região distal pancreática, de limites precisos, paredes espessadas, com conteúdo líquido em seu interior, exercendo efeito compressivo em parede gástrica posterior (Figura I). Submetida à laparotomia, sendo encontrada grande tumoração proveniente da transição entre corpo e cauda pancreática, com aproximadamente $12 \mathrm{~cm} \times 12 \mathrm{~cm} \times 8$ $\mathrm{cm}$, paredes espessadas com limites precisos, não aderida a outros órgãos ou estruturas, não sendo encontradas lesões metastáticas (Figura 2). Realizado pancreatectomia distal e esplenectomia, sendo o tumor retirado com sua cápsula íntegra (Figura 3). A paciente evoluiu com abscesso intracavitário por fístula pancreática, apresentando boa evolução após nova abordagem cirúrgica no $15^{\circ}$ pós-operatório, para drenagem da coleção. $O$ exame anatomopatológico evidenciou neoplasia sólida e cística com cápsula fibrosa espessa, sendo o material enviado para exame imuno-histoquímico, revelando positividade das células neoplásicas para as Citoqueratinas 8 e 18, CD 10 e Receptor de Progesterona (PgR 636), sendo feito o diagnóstico de Tumor de Frantz. Apesar de raro, o tumor de Frantz deve ser suspeitado em mulheres jovens que apresentam tumorações em andar superior de abdome, devido aos resultados favoráveis obtidos após o tratamento cirúrgico.

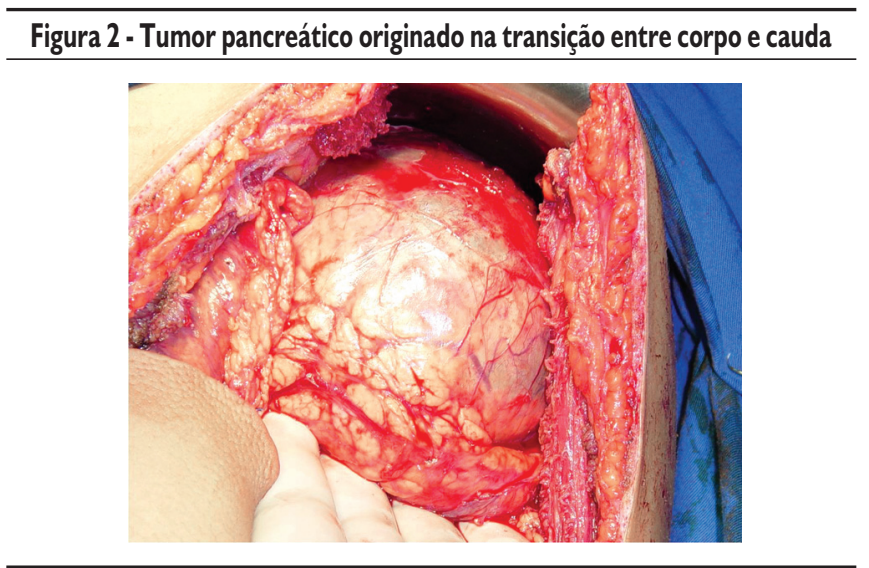

Figura 3 - Tumor ressecado, sendo observado seu aspecto capsulado

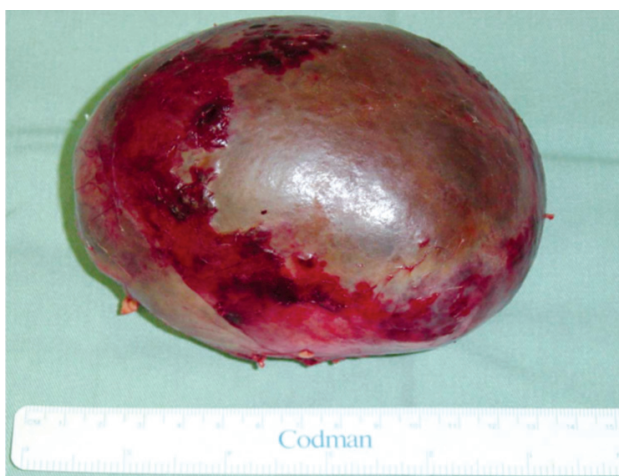

Referências

I. Martin RCG, Klimstra DS, Brennan MF, Conlon KC. Solid-pseudopapillary tumor of the pancreas: a surgical enigma? Ann Surg Oncol. 2002;9( I):35-40. 2.Curvelo LA, Triviño T, Silva MH, Granero LC, Forones NM. Tumor sólidocístico de pâncreas. Relato de caso. Arq Gastroenterol. 1997;34(4):23 I -4. 3.Machado MC, Cunha JE, Bacchella T, Jukemura J, Penteado S, Zerbini MC, et al. Tumor de Frantz (neoplasia epitelial papilar e cistica do pâncreas): estudo de três casos. Rev Hosp Clin Fac Med São Paulo. I 993;48(I):29-34.

4.Takahashi H, Hashimoto K, Hayakawa H, Kusakawa M, Okamura K, Kosaka A, et al. Solid cystic tumor of the pancreas in elderly men: report of a case. Surg Today. 1999;29(12): I 264-7.

5.Lam KY, Lo CY, Fan ST. Pancreatic solid-cystic-papillary tumor: clinicopathologic features in eight patients from Hong Kong and review of the literature. World J Surg. 1999;23( I 0): 1045-50.

6.Saiura A, Umekita N, Matsui Y, Maeshiro T, Miyamoto S, Kitamura M, et al. Successful surgical resection of solid cystic tumor of the pancreas with multiple liver metastases and a tumor thrombus in the portal vein. Hepatogastroenterology. 2000;47(33):887-9.

7.Mao C, Guvendi M, Domenico DR, Kim K, Thomford NR, Howard JM. Papillary cystic and solid tumors of the pancreas: a pancreatic embryonic tumor? Studies of three cases and cumulative review of the world's literature. Surgery. 1995; I 18(5):821-8.

8. Gün F; Celik A; Abbasoglu L; Okumus M; Kapran Y. Solid and cystic tumor of the pancreas: a case report. Acta Chir Belg. 2002; I 02(I):52-3. 